\title{
Doctoral Program Evaluation: An Alternative Approach
}

\author{
Kuan Chen Tsai \\ Dreeben School of Education, University of the Incarnate Word \\ 4301 Broadway, San Antonio, TX, USA \\ E-mail: ktsai@student.uiwtx.edu
}

Received: February 16, 2014 Accepted: March 4, 2014 Published: March 31, 2014

doi:10.5296/iss. v2i1.5401

URL: http://dx.doi.org/10.5296/iss.v2i1.5401

\begin{abstract}
Doctoral degrees may serve as an important impetus that produces independent researchers, scholarship, and future leaders. As a result, it is necessary to evaluate the quality of doctoral programs. This article attempts to use the meta-analysis to evaluate educational research that has been developed at the University of the Incarnate Word. The findings indicate that the majority of students preferred the quantitative paradigm to demonstrate their independent research skills. In this paradigm, the survey approach is the most promising. Evident throughout these discussions is the necessity for more extensive research to be undertaken to track doctoral students and graduates' perceptions of the program. It could be investigated from three phases: past, present, and future.
\end{abstract}

Keywords: doctoral program evaluation, program design, meta-analysis 


\section{Introduction}

Doctoral degrees may serve as an important impe tus that produces independent researchers, scholarship, and future leaders. As a result, it is necessary to evaluate the quality of doctoral programs. However, there are few studies that perform this task (e.g., Alves, Azevedo, \& Gonçalves, 2012; Manathunga, Pitt, \& Critchley, 2009; Stufflebeam, 2001; Terrell, Snyder, Dringus, \& Maddrey, 2012). Manathunga et al. (2009) point out the current trend focuses on "completion and time-to-completion rates or the results of student satisfaction surveys" (p. 92) and further suggest "research needs to be undertaken that identifies the sectors in which research graduates gain employment, how their research education prepared or directed them into these areas, and any gaps in their knowledge and skills" (p. 92). The preceding studies pertain to a quantitative perspective of doctoral program evaluation.

On the other hand, a number of qualitative studies have attempted to capture the unique experience of doctoral students from different stages (e.g., Felder, 2010; Krauss \& Ismail, 2010; Willis \& Carmichael, 2011). According to those findings, they show several salient factors that shape individuals' experience of this journey, including motivation, financial support, and support from doctoral programs, facilities, and peers. Taken as a whole, the standpoint of people, processes, and future outcomes have been investigated in terms of program evaluation. Nevertheless, the view of examining products (dissertations) seems to be absence of this analysis. It is argued that the understanding of quantity and quality of dissertations necessitates the assessment of doctoral education.

Inspired by a typology for creativity research devised by Wehner, Csikszentmihalyi, and Magyari-Beck (1991), this article attempts to use the meta-analysis to evaluate educational research that has been developed at the University of the Incarnate Word. The intention was to understand the status of the doctoral program by examining products (dissertations), the main thematic trends, and methodological approaches. In particular, it seeks to evaluate graduate learning outcomes and to achieve a better understanding of their approaches to complete doctoral education. The rational of analysis of dissertation, as Wehner et al. (1991) argue, is rooted in that "the work of the current graduates is going to shape the publications of the future" (p. 262). Thus, it is hoped that this line of inquiry will gain further insights for future doctoral program design, pedagogy, and teaching practices.

\section{Method}

\subsection{Location of Studies}

The analysis focuses on a set of 181 dissertations in educational sciences that were completed between 2002 and 2012 in the Dreeben School of Education at the University of the Incarnate Word (UIW). The doctoral program in the education department commenced in 1998 and has three concentrations: higher education, international education and entrepreneurship, and organizational leadership. Its main focus is to promote interdisciplinary studies for scholarly research and professional contribution. All studies were analyzed based on a provided abstract. A total of 181 dissertations was obtained for further analysis. 


\section{1) Macrothink}

\subsection{Coding of Data}

The abstract served as the main data resource for further analysis because it summarized the dissertation's key information. All the abstracts are electronically available via an online database. To meet the objective of the current study, the data required to be coded were the following: title of the study, themes, research methodology, theoretical framework, purpose of the study, and main findings of the study. These data were tabulated through a Microsoft Excel program.

\section{Results}

\subsection{Methodological Uses}

This methodological analysis was followed by the typology suggested by Creswell (2007) and Merriam and associates (2002). Basically, three types of research were found:quantitative, qualitative, and mixed-method approaches. For the quantitative perspective, three approaches were employed: survey, correlational, and experimental study. In terms of the qualitative paradigm, eight methods were found: Basic interpretive, phenomenological, case study, narrative, grounded theory, ethnographic, historical, and theoretical approaches.

Table 1 demonstrates that the majority of doctoral candidates (50\%) chose quantitative approaches to complete their degrees. If comparing between quantitative and qualitative methods, the results show $\chi^{2}(1)=3.98, p<.05$, which means there was a significant difference between the two methods, the quantitative being considerably more favorable than the qualitative. Within quantitative approaches, the survey study was the most popular methodology (43\%). On the other hand, within the qualitative paradigm, the most favorable approach was interpretive $(16 \%)$. The mixed-method approach was used in almost one-seventh of the investigations $(13.5 \%)$.

Table 1. Types of dissertation $(n=181)$

\begin{tabular}{lc}
\hline Type of research & Numbers \\
\hline Quantitative & $91(50 \%)$ \\
Survey & $78(43 \%)$ \\
Correlational & $11(6 \%)$ \\
Experimental & $2(1 \%)$ \\
Qualitative & $66(36.5 \%)$ \\
Basic interpretive & $29(16 \%)$ \\
Phenomenological & $9(5 \%)$ \\
Case study & $11(6 \%)$ \\
Narrative & $2(1 \%)$ \\
Grounded theory & $4(2 \%)$ \\
Ethnographic & $6(3 \%)$ \\
Historical & $4(2 \%)$ \\
Theoretical & $1(0.5 \%)$ \\
Mixed & $24(13.5 \%)$ \\
\hline
\end{tabular}




\section{Macrothink}

When analyzed by gender, Table 2 shows the majority of male graduates choose qua ntitative approaches $(30 \%)$, compared to qualitative (15\%). For female graduates, it portrays a different picture. The two paradigms are balanced (21\% vs 22\%). Comparing group differences, the number of males was greater than females in the category of quantitative approaches, but the difference was not significant, $\chi^{2}(1)=2.47, p=.12$. In the qualitative paradigm, females outnumbered males and this difference was also not significant, $\chi^{2}(1)=$ $2.18, p=.14$. In the mixed method, the numbers of both genders were quite balanced.

Table 2. Gender types of dissertation $(n=181)$

\begin{tabular}{lrr}
\hline & Numbers of gender identified & \% of total) \\
\cline { 2 - 3 } Type of research & Male & Female \\
\hline Quantitative & $53(30 \%)$ & $38(21 \%)$ \\
Survey & 45 & 33 \\
Correlational & 7 & 4 \\
Experimental & 1 & 1 \\
Qualitative & $27(15 \%)$ & $39(22 \%)$ \\
Basic interpretive & 15 & 14 \\
Phenomenological & 2 & 7 \\
Case study & 3 & 8 \\
Narrative & 0 & 2 \\
Grounded theory & 2 & 2 \\
Ethnographic & 3 & 3 \\
Historical & 1 & 3 \\
Theoretical & 1 & 0 \\
Mixed & $10(6 \%)$ & $14(8 \%)$ \\
\hline
\end{tabular}

\subsection{Research Themes}

The title, purpose, and main findings of the study were employed to investigate possible themes in this collection of dissertations. As Table 3 demonstrates, eight themes were found, with the most common one located in the category of leadership (29\%). Within this section, teachers, students, supervisors, coaches, and administrators were all investigated. The survey methodology was the common approach in these studies.

Table 3 shows the overall rank order of themes with organization of an educational institution being ranked second at $17 \%$ and learning from others also $17 \%$. Organization of an educational institution includes diverse perspectives, but mainly focuses on its development. Learning from others was also in the second highest category. The majority of studies utilized a qualitative approach to understand the unique experience of a small number of people and attempted to develop an overarching theme for describing that phenomenon. 
Table 3. Research themes $(n=181)$

\begin{tabular}{lc}
\hline Theme of research & Numbers identified $(\%)$ \\
\hline Organization of an educational institution & $30(17 \%)$ \\
Educational system & $10(6 \%)$ \\
Pedagogy & $15(8 \%)$ \\
Educational learning process & $15(8 \%)$ \\
Program evaluation & $8(4 \%)$ \\
Learning from others & $30(17 \%)$ \\
Leadership & $52(29 \%)$ \\
Organizational development & $21(12 \%)$ \\
\hline
\end{tabular}

\section{Discussion and Conclusions}

This study highlights the diverse approaches that graduates may employ to complete their doctoral education. It demonstrates a possible path to understand doctoral programs from the perspective of dissertations (products). Importantly, it also highlights several implications for doctoral program design, pedagogy, and teaching practices. Having reviewed doctoral dissertations included in the period 2002-2012 in the Dreeben School of Education, the findings paint an overall picture of inquiry into the main trends in this research community.

It would be valuable to inspect the total trend of dissertations, thereby assisting students to translate research skills learned across diverse classroom experiences into their final product. The findings indicate that the majority of students preferred the quantitative paradigm to demonstrate their independent research skills. Although male graduates outnumber females in the quantitative paradigm and conversely female graduates outnumber their counterparts in the qualitative approach, the difference is not significant. It possibly indicates the likelihood of well-balanced research skill development in this community. In other words, there is no askew tendency of the two paradigms in terms of genders.

The survey approach is the most promising. The main reason for this trend might reveal students themselves for future considerations of job hunting. A large portion of studies emphasizes leadership perspectives and most students are seeking leadership positions in organizational settings. As a consequence, the survey methodology still dominates in organizational literature, which in turn affects students' options. It may also indicate faculty and the program itself place more emphasis on quantitative perspectives of scientific research. In fact, until recently (2009), the qualitative research class was the core course in the program. This might explain why most students pursued numerical analysis rather than text analysis for their research.

This result leads to the second reflection on the doctoral program. It is believed that a sound researcher should appreciate and understand the benefits of two paradigms (qualitative and quantitative). Hence, some researchers choose the mixed-method approach to obtain a more holistic picture of a research target. Following this notion, during the training process, doctoral education plays an important role in supporting this idea and practice. This study 
confirms that the inclusion of qualitative research courses into the requirement of doctoral education has produced more inquiries in this direction, even though it accounts for $36.5 \%$ of total output. In the near future, it might achieve an equal situation with the comparison of quantitative studies. In designing programs for doctoral education, it is advisable to keep a balanced position between the two paradigms. Under the umbrella of scientific research, numbers are still more persuasive than words; however, with the consensus of the scientific community, it is more acceptable to include individuals' voices as a key element of critical research.

Finally, in choosing areas for future doctoral program development, it might be opportune to encourage doctoral students to integrate two paradigms (mixed-method) to achieve a better understanding of the investigated phenomena. Additionally, evident throughout these discussions is the necessity for more extensive research to be undertaken to track doctoral students and graduates' perceptions of the program. It could be investigated from three phases: past, present, and future. For example, before students begin their doctoral education, a survey could be distributed for the examination of their past experience, perspectives of current program, and future goals. When they are in the second or third year, another survey could be developed for the examination of their current perceptions of the program, advantages and disadvantages, and pitfalls they face in this journal. Finally, graduates could be asked to provide their insights on their total doctoral education experience. Since they have finished this journey and may have suggestions to enhance the program. It is suggested that using focus groups is also an important tool for evaluation. Within these three stages (past, present, and future), data from the interview will provide useful insights or feedback for the improvement of the program. This valuable information will then be considered in rethinking not only pedagogy and educational practices, but also meeting individuals' learning needs by acquiring core competencies with the adjustment of the curriculum. It is important to remember that graduates' future successes (career goals) are partly dependent on sound education programs (academic needs).

\section{References}

Alves, M. G., Azevedo, N. R., \& Gonçalves, T. N. R. (2012). Educational research and doctoral dissertations: A review within a research community. Qualitative Inquiry, 18(7), 626-637.

Creswell, J. W. (2007). Educational research: Planning, conducting, and evaluating quantitative and qualitative research. Boston, MA: Pearson Education.

Felder, P. (2010). On doctoral student development: Exploring faculty mentoring in the shaping of African American doctoral student success. The Qualitative Report, 15(2), 455-474. Retrieved from http//www.nova.edu/ssss/QR/QR15-2/felder.pdf

Krauss, S. E., \& Ismail, I. A. (2010). PhD students' experiences of thesis supervision in Malaysia: Managing relationships in the midst of institutional change. The Qualitative Report, 15(4), 802-822. Retrieved from http:/www.nova.edu/ssss/QR/QR15-4/krauss.pdf

Manathunga, C., Pitt, R., \& Critchley, C. (2009). Graduate attribute development and employment outcomes: tracking $\mathrm{PhD}$ graduates. Assessment \& Evaluation in Higher 


\section{Macrothink}

Education, 34(1), 91-103. http://dx.doi.org/10.1080/02602930801955945

Merriam, S. B., \& Associates (2002). Qualitative research in practice: Examples for discussion and analysis. San Francisco, CA: Jossey-Bass.

Stufflebeam, D. L. (2001). Interdisciplinary Ph.D. programming in evaluation. American Journal of Evaluation, 22(3), 445-455.

Terrell, S. R., Snyder, M. M., Dringus, L. P., \& Maddrey, E. (2012). A grounded theory of connectivity and persistence in a limited residency doctoral program. The Qualitative Report, 17(62), 1-14. Retrieved from http//www.nova.edu/ssss/QR/QR17/terrell.pdf

Wehner, L., Csikszentmihalyi, M., \& Magyari-Beck, I. (1991). Current approaches used in studying creativity: An exploratory investigation. Creativity Research Journal, 4(3), 261-271.

Willis, B., \& Carmichael, K. D. (2011). The lived experience of late-stage doctoral student attrition in counselor education. The Qualitative Report, 16(1), 192-207. Retrieved from http://www.nova.edu/ssss/QR/QR16-1/willis.pdf 